Archive for

Organic Chemistry

Arkivoc 2018, part vii, 0-0

\title{
Synthesis and anti-proliferative activity of novel oxepin-annulated coumarins
}

\author{
Saisuree Prateeptongkum, ${ }^{* a}$ Wiratchanee Mahavorasirikul, ${ }^{b}$ and Nongnaphat Duangdee ${ }^{b}$ \\ ${ }^{a}$ Department of Chemistry, Faculty of Science and Technology, Thammasat University, Pathumthani 12121, \\ Thailand \\ ${ }^{b}$ Drug Discovery and Development Center, Office of Advanced Science and Technology, Thammasat University, \\ Pathumthani 12121, Thailand \\ Email: saisuree@tu.ac.th, saisuree@gmail.com
}

Received 02-26-2018

Accepted 08-10-2018

Published on line 09-02-2018

\section{Abstract}

A series of fused dihydrooxepino[ $h]$ - and dihydrooxepino[g]coumarins (7 and 8) were synthesized through allylation, Claisen rearrangement, allylation and ring-closing metathesis (RCM), respectively. All the synthesized compounds were characterized by appropriate spectral analysis. The anti-proliferative activities of compound 5a-c, 6a, 6c, 7a-c and 8a-c were evaluated against human colon cancer (Caco-2), liver cancer (HepG2) and breast cancer (SKBR-3) cell lines using tamoxifen (TAM) as the positive control. Compound 7b showed significant anti-proliferative activity against resistant Caco-2 and SKBR-3 cell lines on comparison with all other coumarin derivatives. Interestingly, compound $\mathbf{8 b}$ was more potent than TAM against sensitive HepG2 cell line.
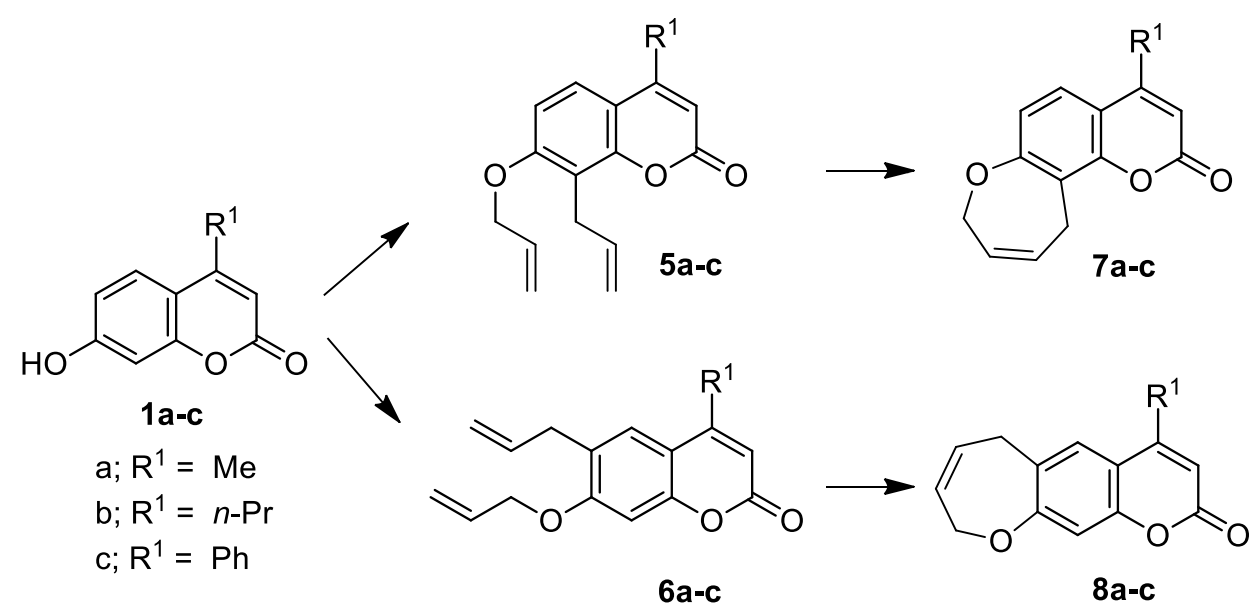

Keywords: Claisen rearrangement, ring-closing metathesis, coumarin, oxepine, anti-proliferative activity 


\section{Introduction}

Coumarins fused with 5- and 6-membered oxygen heterocycle, known as furocoumarins and pyranocoumarins, respectively, (Figure 1) are important structural units in many natural products and biologically active compounds. They exhibit a wide spectrum of pharmaceutical and biological properties, including anti-inflammatory, ${ }^{1,2}$ anti-HIV, ${ }^{3}$ anticancer, ${ }^{4,5}$ antioxidative, ${ }^{6}$ antifungal, ${ }^{7}$ antimicrobial, ${ }^{8}$ antibacterial, ${ }^{9}$ anticoagulant, ${ }^{10}$ anticonvulsant, ${ }^{11}$ vasorelaxant ${ }^{12}$ activities.

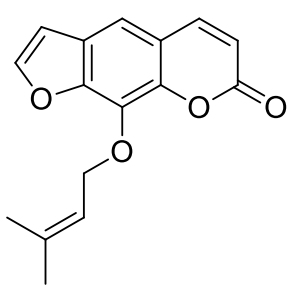

Imperatorin<smiles>CC(C)=CCc1c2occc2c(O)c2ccc(=O)oc12</smiles>

Alloisoimperatorin<smiles>COc1c2ccoc2c(O)c2oc(=O)ccc12</smiles>

9-Hydroxy-4-methoxypsoralen

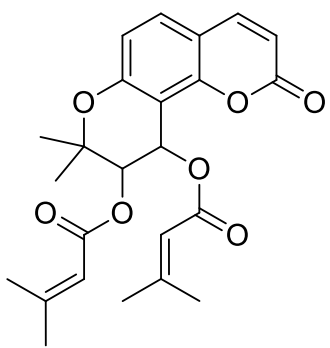

Disenecioyl Khellactone

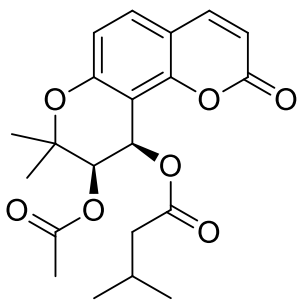

Suksdorfin

Figure 1. Examples of bioactive furocoumarins and pyranocoumarins.

Various natural products and bioactive compounds containing oxepane ring, 7-membered oxygen heterocycle, ${ }^{13-17}$ have been also reported with a broad range of interesting biological activities such as antidepressant, $^{18}$ analgesic, ${ }^{19}$ antipsychotic, ${ }^{20}$ antioxidant, ${ }^{21}$ antimycobacterial ${ }^{17,22}$ and anticancer ${ }^{23,24}$ (Figure 2).

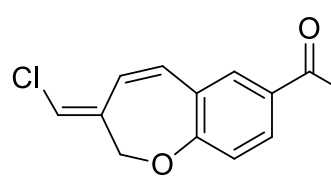

Pterulone<smiles>O=C(O)Cc1cc2cc3c(cc2o1)OCC(=CCl)C=C3</smiles>

Pterulinic acid<smiles>[R]C1=CCc2c(cc3oc([R])cc(=O)c3c2O)OC1</smiles>

Ptaeroxylin; $\quad \mathrm{R}^{1}=\mathrm{R}^{2}=\mathrm{Me}$ Karenin; $\quad \mathrm{R}^{1}=\mathrm{CH}_{2} \mathrm{OH}, \mathrm{R}^{2}=\mathrm{Me}$ Ptaeroxylinol; $\mathrm{R}^{1}=\mathrm{Me}, \mathrm{R}^{2}=\mathrm{CH}_{2} \mathrm{OH}$<smiles>[R2]Oc1ccc([R8])c2c1C=Cc1c([R])c([R])c(C)c(O[R])c1O2</smiles>

$\mathrm{R}^{3}$

Pacharin; $\mathrm{R}^{1}, \mathrm{R}^{3}, \mathrm{R}^{4}, \mathrm{R}^{5}=\mathrm{H}, \mathrm{R}^{2}=\mathrm{CH}_{3}$ Bauhiniastatin 2; $\mathrm{R}^{1}, \mathrm{R}^{4}, \mathrm{R}^{5}=\mathrm{H}, \mathrm{R}^{2}=\mathrm{CH}_{3}, \mathrm{R}^{3}=\mathrm{OCH}_{3}$ Bauhiniastatin 3; $\mathrm{R}^{1}, \mathrm{R}^{3}=\mathrm{H}, \mathrm{R}^{2}, \mathrm{R}^{4}=\mathrm{CH}_{3}, \mathrm{R}^{5}=\mathrm{OH}$ Bauhiniastatin 4; $\mathrm{R}^{1}=\mathrm{CH}_{3}, \mathrm{R}^{2}, \mathrm{R}^{3}, \mathrm{R}^{4}, \mathrm{R}^{5}=\mathrm{H}$

Figure 2. Examples of natural products and bioactive compounds containing 7-membered oxygen heterocycle.

Coumarins fused with heterocycles have gained much attention due to their potential biological activities. However, synthetic study and the evaluation for biological activities of medium ring oxacycle fused coumarins, especially oxepinocoumarins are scarce. ${ }^{25,26}$ 
Among several methods for the construction of cyclic structures, ${ }^{27-32}$ ring-closing metathesis (RCM) has proven to be a powerful method for the synthesis of carbocycles and heterocycles with various ring sizes. ${ }^{33-38}$

In continuation to our previous work on the synthesis of coumarin derivatives, ${ }^{39}$ we wish to report here the synthesis of fused-dihydrooxepino[g]- and [h]coumarins through the combination of allylation, Claisen rearrangement, allylation and RCM, respectively. Moreover, the evaluation of anticancer activity of compounds 5a-c, 6a, 6c, 7a-c and 8a-c against Caco-2, HepG2 and SKBR-3 cell lines was performed.

\section{Result and Discussion}

The synthesis of the target compounds $\mathbf{7}$ and $\mathbf{8}$ was carried out as described in Scheme 1. Coumarins (1a-c) were efficiently converted to the corresponding allyloxy coumarins (2a-c) in high yields (89-92\%) by treatment with allyl bromide and $\mathrm{K}_{2} \mathrm{CO}_{3}$ under reflux in acetone for $16 \mathrm{~h}$. The Claisen rearrangement of $2 \mathrm{a}-\mathrm{c}$ was carried out in ethylene glycol at $190^{\circ} \mathrm{C}$ in sand bath for $24 \mathrm{~h}$ leading to mixtures of respective regioisomers 3a-c and 4a-c in 45-96\% combined yields.

The ratios of two regioisomers 3 and 4 were determined by ${ }^{1} \mathrm{H}$ NMR spectra of pure mixtures by comparing the integration areas of $\mathrm{H}^{5}$ on the benzene rings of compounds 3 and $4 .{ }^{1} \mathrm{H} N M R$ chemical shifts and splitting patterns of two protons on phenyl rings of $\mathbf{3}$ and $\mathbf{4}$ are listed on table 1 . Because these two regioisomers were difficult to separate by standard chromatographic purification, we decided to use them as regioisomeric mixtures for the next allylation reaction.

Table 1. ${ }^{1} \mathrm{H}$ NMR (400 MHz, DMSO- $d_{6}$ ) of selected protons on benzene ring of compounds 3 and 4 and the calculated ratio of $\mathbf{3}$ and $\mathbf{4}$

\begin{tabular}{llllll}
\hline & \multicolumn{2}{c}{$\delta$ of 3 (ppm) } & \multicolumn{2}{c}{$\delta$ of 4 (ppm) } & Ratio of 3:4 \\
\cline { 2 - 5 } & $\mathrm{H}^{5}$ & $\mathrm{H}^{6}$ & $\mathrm{H}^{5}$ & $\mathrm{H}^{8}$ & \\
\hline a & $7.50(\mathrm{~d}, J 8.8 \mathrm{~Hz})$ & $6.89(\mathrm{~d}, J 8.8 \mathrm{~Hz})$ & $7.43(\mathrm{~s})$ & $6.75(\mathrm{~s})$ & $13.3: 1$ \\
b & $7.52(\mathrm{~d}, J 8.8 \mathrm{~Hz})$ & $6.86(\mathrm{~d}, J 8.8 \mathrm{~Hz})$ & $7.44(\mathrm{~s})$ & $6.73(\mathrm{~s})$ & $4.8: 1$ \\
c & $7.13(\mathrm{~d}, J 8.8 \mathrm{~Hz})$ & $6.82(\mathrm{~d}, J 8.8 \mathrm{~Hz})$ & $7.08(\mathrm{~s})$ & $6.82(\mathrm{~s})$ & $4.5: 1$ \\
\hline
\end{tabular}

After completion of the allylation reaction and purification, compounds 5a-c and 6a-c were obtained as pure regioisomers in 64-70\% and 9-15\% yields, respectively. The RCM reactions of olefins 5a-c and 6a-c with Grubbs' first-generation catalyst in dichloromethane at room temperature for $24 \mathrm{~h}$ gave the expected metathesis products $7 \mathrm{a}-\mathrm{c}$ and $\mathbf{8 a - c}$ in good yields (64-82\%).

The synthesized compounds 5-8, except for $\mathbf{6 b}$, were evaluated for their in vitro antiproliferative activity against three cancer cell lines including colorectal adenocarcinoma (Caco-2), hepatocellular carcinoma (HepG2) and breast carcinoma (SKBR-3) cell lines using MTT assay. The concentration-response studies were performed in order to determine their half-medium inhibitory concentration (IC 50 ) values (Table 2 ) by incubation of cell lines with 11 compounds at concentrations of $0-100 \mu \mathrm{g} / \mathrm{mL}$ for $48 \mathrm{~h}$ at $5 \% \mathrm{CO}_{2}$ and $37^{\circ} \mathrm{C}$. Tamoxifen was also evaluated as references. 


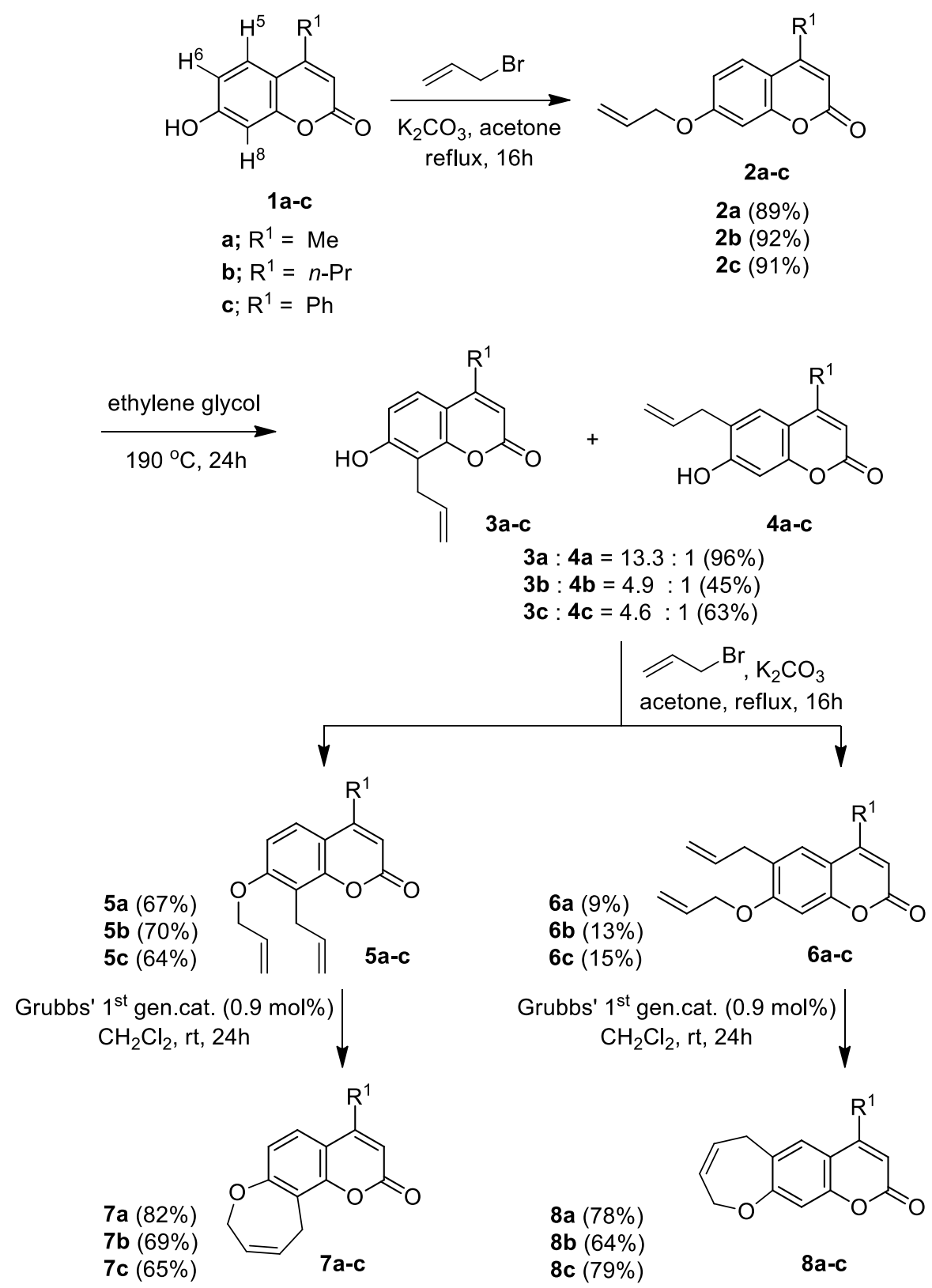

Scheme 1. Synthesis of fused dihydrooxepino[ $h]$ - and dihydrooxepino[g]coumarins (7 and 8).

From the analysis of Table 2 , it can be concluded that compound $7 \mathbf{b}$ was the most cytotoxic to Caco-2 and SKBR-3 cell lines with $\mathrm{IC}_{50}$ of $30.05 \pm 0.71$ and $11.18 \pm 1.93 \mu \mathrm{g} / \mathrm{mL}$, respectively. It also showed potent activity on HepG2 cell with $\mathrm{IC}_{50}$ values of $15.32 \pm 0.30 \mu \mathrm{g} / \mathrm{mL}$. Interestingly, compound $\mathbf{8 b}$ has demonstrated the most promising activity against HepG2 cell line with $\mathrm{IC}_{50}$ values of $8.78 \pm 1.21 \mu \mathrm{g} / \mathrm{mL}$, which is lower than that of tamoxifen, $5 \mathbf{a}$ and $\mathbf{5 b}\left(\mathrm{IC}_{50}\right.$ values of $9.41 \pm 1.81,10.48 \pm 3.44$ and $10.42 \pm 2.16 \mu \mathrm{g} / \mathrm{mL}$, respectively). Comparison of the substitution at the C-4 position of the coumarin ring suggested that the propyl group contributed to the anti-proliferative activity enhancement. Compounds $\mathbf{5 b} \mathbf{b} \mathbf{7} \mathbf{b}$ and $\mathbf{8 b}$ were more active than compounds $\mathbf{5 a , c}, \mathbf{7 a}, \mathbf{c}$ and $\mathbf{8 a}, \mathbf{c}$, respectively against almost all tested cell lines. In addition, the nature of the angularly or linearly fused ring ( $\mathbf{7}$ or $\mathbf{8}$ ) did not significantly affect the activity. Among the tested cell lines, HepG2 has proven to be the most sensitive cell line. Approximately half of the tested coumarin derivatives presented high cytotoxicity $\left(\mathrm{IC}_{50} \leq 20 \mu \mathrm{g} / \mathrm{mL}\right)$. On the other hand, Caco-2 has proven to be the most resistant cell line, since almost all compounds exhibited moderate cytotoxicity (IC 50 ranged between 21 and $200 \mu \mathrm{g} / \mathrm{mL}$ ). 
Table 2. $I C_{50}$ values of coumarin derivatives 5-8 and tamoxifen against Caco-2, HepG2 and SKBR-3 cancer cell lines using MTT assay ${ }^{a}$<smiles>[R16]c1cc(=O)oc2c(CC=C)c(OCC=C)ccc12</smiles><smiles>[R]c1cc(=O)oc2cc(OCC=C)c(CC=C)cc12</smiles><smiles>[R]c1cc(=O)oc2c3c(ccc12)OCC=CC3</smiles><smiles>[R]c1cc(=O)oc2cc3c(cc12)CC=CCO3</smiles>

$$
\mathbf{a} ; R^{1}=\operatorname{Me} \quad \mathbf{b} ; R^{1}=n-\operatorname{Pr} \quad \mathbf{c} ; R^{1}=P h
$$

\begin{tabular}{llll}
\hline \multirow{2}{*}{ Compound } & \multicolumn{3}{c}{$\mathrm{IC}_{50}(\mu \mathrm{g} / \mathrm{mL})$} \\
\cline { 2 - 4 } & Caco-2 & HepG2 & SKBR-3 \\
\hline 5a & $>500$ & $10.48 \pm 3.44$ & $38.80 \pm 3.19$ \\
5b & $105.22 \pm 0.72$ & $10.42 \pm 2.16$ & $165.61 \pm 9.57$ \\
$\mathbf{5 c}$ & $49.10 \pm 7.05$ & $41.61 \pm 3.49$ & $59.70 \pm 14.35$ \\
$\mathbf{6 a}$ & $>500$ & $59.04 \pm 4.30$ & $101.21 \pm 20.23$ \\
$\mathbf{6 c}$ & $51.02 \pm 24.11$ & $21.05 \pm 3.36$ & $30.80 \pm 1.42$ \\
7a & $55.54 \pm 21.18$ & $18.64 \pm 1.94$ & $42.77 \pm 2.43$ \\
7b & $30.05 \pm 0.71$ & $15.32 \pm 0.30$ & $11.18 \pm 1.93$ \\
7c & $35.29 \pm 1.24$ & $37.77 \pm 8.52$ & $196.34 \pm 2.03$ \\
8a & $96.72 \pm 9.15$ & $24.3 \pm 0.51$ & $63.76 \pm 17.67$ \\
8b & $73.04 \pm 7.82$ & $8.78 \pm 1.21$ & $30.79 \pm 8.50$ \\
8c & $>500$ & $16.37 \pm 2.27$ & $28.33 \pm 12.68$ \\
Tam & $17.77 \pm 2.79$ & $9.41 \pm 1.81$ & $10.96 \pm 1.85$ \\
\hline
\end{tabular}

${ }^{a}$ Values represent mean \pm standard deviation of three parallel measurements. The criteria used to categorize the cytotoxicity of coumarin derivatives against cancer cell lines, based on U.S. National Cancer Institute (NCI) and Geran protocol ${ }^{40}$ were as follows: $I_{50} \leq 20 \mu \mathrm{g} / \mathrm{mL}=$ highly cytotoxic, $\mathrm{IC}_{50}$ ranged between 21 and 200 $\mu \mathrm{g} / \mathrm{mL}=$ moderately cytotoxic, $\mathrm{IC}_{50}$ ranged between 201 and $500 \mu \mathrm{g} / \mathrm{mL}=$ weakly cytotoxic and $\mathrm{IC}_{50}>501$ $\mu \mathrm{g} / \mathrm{mL}=$ no cytotoxicity.

\section{Conclusions}

We have demonstrated a simple synthetic strategy for synthesis of fused-dihydrooxepino[g]- and [h]coumarins $\mathbf{7}$ and $\mathbf{8}$ via the allylation, Claisen rearrangement, allylation and RCM, respectively. The antiproliferative activity of compound $\mathbf{5 a - c}, \mathbf{6 a}, \mathbf{6 c}, \mathbf{7 a - c}$ and $\mathbf{8 a - c}$ was screened against Caco-2, HepG2 and SKBR-3 cell lines using tamoxifen (TAM) as the positive control. Compound $\mathbf{7 b}$ exhibited similar anti-proliferative activity against resistant SKBR-3 cell to TAM and demonstrated the most potent activity against Caco-2 among the tested coumarin derivatives. Compound $\mathbf{8} \mathbf{b}$ displayed the most potent anti-proliferative activity against HepG2 cell line. Our results could be used as a starting point for development of powerful coumarin anticancer therapies. 


\section{Experimental Section}

General. Melting points $\left({ }^{\circ} \mathrm{C}\right)$ were measured with the Gallenkamp melting point apparatus and are uncorrected. ${ }^{1} \mathrm{H}$ and ${ }^{13} \mathrm{C}$ NMR spectra were recorded on a Bruker AV400 spectrometer. Chemical shifts $(\delta)$ are given in ppm and refer to TMS or the residual undeuterated solvent as the internal standard. The following abbreviations are used: $\mathrm{s}=$ singlet, $\mathrm{d}=$ doublet, $\mathrm{t}=$ triplet, $\mathrm{q}=$ quartet, quint $=$ quintet, sext $=\mathrm{sextet}, \mathrm{m}=$ multiplet, $\mathrm{dd}=$ double doublet, br.s = broad singlet. ESI mass spectra were recorded on a Thermo Finnigan LCQ Advantage Mass Spectrometer. High Resolution Mass Spectrometry was performed with a MicroTOFLC, Bruker Daltonics. FTIR spectra were obtained with a Perkin Elmer FT-IR Spectrum GX. Column chromatography was performed on silica gel (Kieselgel 60, 70-230 mesh, Merck) in common glass columns. Preparative TLC was carried out on silica gel plate (Merck silica gel 60 PF254). All chemicals were obtained from commercial suppliers, and were used without further purification. The required coumarin precursors 1a-c were prepared via Pechmann reaction. ${ }^{39}$

General procedure for allylation of 1a-c. To a solution of phenol derivative $(\mathbf{1}, 10 \mathrm{mmol})$ anhydrous $\mathrm{K}_{2} \mathrm{CO}_{3}$ $(4.15 \mathrm{~g}, 30 \mathrm{mmol})$ in acetone $(30 \mathrm{~mL})$ was added allyl bromide $(1.81 \mathrm{~g}, 15 \mathrm{mmol})$. The mixture was heated under reflux and stirring for 16-18 $\mathrm{h}$. After cooling to room temperature, the precipitated solid was filtered and washed with acetone. The filtrate was concentrated under reduced pressure and purified by column chromatography on silica gel using EtOAc/hexane as eluent to afford the corresponding allylic ether 2. ${ }^{25,26}$

7-(Allyloxy)-4-methyl-2H-chromen-2-one (2a). Yield 89\%; white solid; mp 100-102 ${ }^{\circ} \mathrm{C}$ (from EtOAc-Hexanes) (lit $\left.{ }^{41} \mathrm{mp} \mathrm{100-101}{ }^{\circ} \mathrm{C}\right) ; \mathrm{R}_{f} 0.68$ (20\% EtOAc/hexanes); IR (KBr): $v_{\max } 3076,3020,2953,1725,1611,1392,1349$, $1285,1263,1208,1141,1069,994,936,857,838,810 \mathrm{~cm}^{-1} ;{ }^{1} \mathrm{H}$ NMR $\left(400 \mathrm{MHz}^{\mathrm{CDCl}}\right.$ ) : $\delta 7.49(\mathrm{~d}, J 8.8 \mathrm{~Hz}, 1 \mathrm{H})$, $6.88(\mathrm{dd}, J$ J 8.8, $2.4 \mathrm{~Hz}, 1 \mathrm{H}), 6.83(\mathrm{~d}, J 2.4 \mathrm{~Hz}, 1 \mathrm{H}), 6.14(\mathrm{~s}, 1 \mathrm{H}), 6.11-5.94(\mathrm{~m}, 1 \mathrm{H}), 5.44(\mathrm{dd}, J 17.2,1.0 \mathrm{~Hz}, 1 \mathrm{H})$, $5.34(\mathrm{dd}, J$ 10.6, $0.6 \mathrm{~Hz}, 1 \mathrm{H}), 4.60$ (d, J $5.2 \mathrm{~Hz}, 2 \mathrm{H}), 2.40(\mathrm{~s}, 3 \mathrm{H}) ;{ }^{13} \mathrm{C} \mathrm{NMR}(100 \mathrm{MHz}, \mathrm{CDCl}$ ) : $\delta 161.63$ (C), 161.26 $(\mathrm{C}), 157.26(\mathrm{C}), 152.50(\mathrm{C}), 132.25(\mathrm{CH}), 125.54(\mathrm{CH}), 118.48\left(\mathrm{CH}_{2}\right), 113.74(\mathrm{C}), 112.81(\mathrm{CH}), 112.06(\mathrm{CH}), 101.82$ (CH), $69.26\left(\mathrm{CH}_{2}\right), 18.63\left(\mathrm{CH}_{3}\right) ; \mathrm{MS}\left(\mathrm{ESI}^{+}\right) \mathrm{m} / \mathrm{z}(\%) 217.0\left(\mathrm{M}+\mathrm{H}^{+}, 100\right)$.

7-(Allyloxy)-4-propyl-2H-chromen-2-one (2b). ${ }^{42}$ Yield 92\%; light yellow oil; $\mathrm{R}_{f} 0.57$ (20\% EtOAc/hexanes); IR (nujol): $v_{\max } 3082,2963,2934,2875,2402,1732,1614,1557,1510,1456,1392,1277,1201,1146,1100,1012$, 843, $580 \mathrm{~cm}^{-1} ;{ }^{1} \mathrm{H}$ NMR (400 MHz, CDCl$): \delta 7.51(\mathrm{~d}, J 8.8 \mathrm{~Hz}, 1 \mathrm{H}), 6.86(\mathrm{dd}, J$ 8.6, $2.4 \mathrm{~Hz}, 1 \mathrm{H}), 6.81(\mathrm{~d}, J 2.4 \mathrm{~Hz}$, $1 \mathrm{H}), 6.10(\mathrm{~s}, 1 \mathrm{H}), 6.10-5.95(\mathrm{~m}, 1 \mathrm{H}), 5.43(\mathrm{~d}, J 17.2 \mathrm{~Hz}, 1 \mathrm{H}), 5.32(\mathrm{~d}, J 10.4 \mathrm{~Hz}, 1 \mathrm{H}), 4.59(\mathrm{~d}, J 5.2 \mathrm{~Hz}, 2 \mathrm{H}), 2.69(\mathrm{t}$, J 7.6 Hz, 2H), 1.71 (sext, J 7.6 Hz, 2H), 1.04 (t, J 7.6 Hz, 3H); $\left.{ }^{13} \mathrm{C} \mathrm{NMR} \mathrm{(100} \mathrm{MHz,} \mathrm{CDCl}\right): \delta 161.45$ (C), 161.35 (C), $156.14(\mathrm{C}), 155.50(\mathrm{C}), 132.27(\mathrm{CH}), 125.27(\mathrm{CH}), 118.33\left(\mathrm{CH}_{2}\right), 113.05(\mathrm{C}), 112.71(\mathrm{CH}), 110.92(\mathrm{CH}), 102.00$ $\left.(\mathrm{CH}), 69.21\left(\mathrm{CH}_{2}\right), 33.74\left(\mathrm{CH}_{2}\right), 21.46\left(\mathrm{CH}_{2}\right), 13.84\left(\mathrm{CH}_{3}\right) ; \mathrm{MS}(\mathrm{ESI})^{+}\right) \mathrm{m} / \mathrm{z}(\%) 245.5\left(\mathrm{M}+\mathrm{H}^{+}, 100\right)$.

7-(Allyloxy)-4-phenyl-2H-chromen-2-one (2c). Yield 91\%; white solid; mp 85-88 ${ }^{\circ} \mathrm{C}$ (from EtOAc-Hexanes) (lit ${ }^{43}$ $\left.\mathrm{mp} 85-87^{\circ} \mathrm{C}\right) ; \mathrm{R}_{f} 0.80$ (40\% EtOAc/hexanes); IR (neat): $v_{\max } 3080,1727,1615,1550,1375,1309,1284,1153$, $1125,1023,938,857,777,713 \mathrm{~cm}^{-1} ;{ }^{1} \mathrm{H}$ NMR $\left(400 \mathrm{MHz}, \mathrm{CDCl}_{3}\right): \delta 7.56-7.39(\mathrm{~m}, 5 \mathrm{H}), 7.38(\mathrm{~d}, J 9.2 \mathrm{~Hz}, 1 \mathrm{H}), 6.90$ (d, J $2.4 \mathrm{~Hz}, 1 \mathrm{H}), 6.81(\mathrm{dd}, J$ 8.6, $2.4 \mathrm{~Hz}, 1 \mathrm{H}), 6.22(\mathrm{~s}, 1 \mathrm{H}), 6.20-5.85(\mathrm{~m}, 1 \mathrm{H}), 5.42(\mathrm{dd}, J 17.3,1.4 \mathrm{~Hz}, 1 \mathrm{H}), 5.34$ (dd, J 10.5, $1.3 \mathrm{~Hz}, 1 \mathrm{H}), 4.59$ (d, J $5.3 \mathrm{~Hz}, 2 \mathrm{H}) ;{ }^{13} \mathrm{C} \mathrm{NMR}\left(100 \mathrm{MHz}, \mathrm{CDCl}_{3}\right): \delta 161.74(\mathrm{C}), 161.18$ (C), 155.94 (C), $155.79(\mathrm{C}), 135.58(\mathrm{C}), 132.16(\mathrm{CH}), 129.59(\mathrm{CH}), 128.83(2 \mathrm{CH}), 128.38(2 \mathrm{CH}), 127.99(\mathrm{CH}), 118.55\left(\mathrm{CH}_{2}\right), 112.81$ $(\mathrm{CH}), 112.65(\mathrm{C}), 111.94(\mathrm{CH}), 102.02(\mathrm{CH}), 69.28\left(\mathrm{CH}_{2}\right) ; \mathrm{MS}\left(\mathrm{ESI}^{+}\right) \mathrm{m} / \mathrm{z}(\%) 279.2\left(\mathrm{M}+\mathrm{H}^{+}, 100\right)$.

General procedure for Claisen rearrangement of 2a-c. A solution of allylic ether (2) (9 mmol) in ethylene glycol $(45 \mathrm{~mL})$ was heated under stirring at $190{ }^{\circ} \mathrm{C}$ in sand bath for $24 \mathrm{~h}$. After cooling to room temperature, the mixture was quenched with water $(50 \mathrm{~mL})$ and the aqueous phase was extracted with EtOAc $(3 \times 45 \mathrm{~mL})$. The organic phases were combined, dried over anhydrous $\mathrm{Na}_{2} \mathrm{SO}_{4}$ and concentrated in vacuo and the residue 
was purified by column chromatography on silica gel using EtOAc/hexane as eluent to give a mixture of regioisomers of $\mathbf{3}$ as a major product and $\mathbf{4}$ as a minor product. ${ }^{1} \mathrm{H}$ NMR and ${ }^{13} \mathrm{C}$ NMR were characterized only the major products. ${ }^{26}$

8-Allyl-7-hydroxy-4-methyl-2H-chromen-2-one (3a) and 6-allyl-7-hydroxy-4-methyl-2H-chromen-2-one (4a). Yield 96\% (3a:4a 93:7); pale yellow solid; $m p 189-190{ }^{\circ} \mathrm{C}$ (from EtOAc-Hexanes); $\mathrm{R}_{f}$ (3a) 0.33, $\mathrm{R}_{f}$ (4a) 0.43 (33\% EtOAc/hexanes); IR (KBr): $v_{\max } 3220,1688,1606,1566,1387,1318,1049 \mathrm{~cm}^{-1} ;{ }^{1} \mathrm{H}$ NMR $\left(400 \mathrm{MHz}\right.$, DMSO- $\left.d_{6}\right): \delta$ $10.46(\mathrm{~s}, 1 \mathrm{H}), 7.50(\mathrm{~d}, J 8.8 \mathrm{~Hz}, 1 \mathrm{H}), 6.89(\mathrm{~d}, J 8.8 \mathrm{~Hz}, 1 \mathrm{H}), 6.13(\mathrm{~s}, 1 \mathrm{H}), 6.09-5.80(\mathrm{~m}, 1 \mathrm{H}), 5.05-4.96(\mathrm{~m}, 2 \mathrm{H})$, 3.45 (d, J $6.0 \mathrm{~Hz}, 2 \mathrm{H}), 2.37$ (s, 3H); ${ }^{13} \mathrm{C}$ NMR (100 MHz, DMSO-d $\left.d_{6}\right): \delta 160.75$ (C), 160.70 (C), 159.23 (C), 154.13 (C), $153.16(\mathrm{C}), 135.93(\mathrm{CH}), 124.33(\mathrm{CH}), 115.45\left(\mathrm{CH}_{2}\right), 113.33(\mathrm{C}), 112.53(\mathrm{CH}), 110.47(\mathrm{CH}), 26.97\left(\mathrm{CH}_{2}\right), 18.48$ $\left(\mathrm{CH}_{3}\right) ; \mathrm{MS}\left(\mathrm{ESI}^{+}\right) \mathrm{m} / \mathrm{z}(\%) 217.5\left(\mathrm{M}+\mathrm{H}^{+}, 100\right)$.

8-Allyl-7-hydroxy-4-propyl-2H-chromen-2-one (3b) and 6-allyl-7-hydroxy-4-propyl-2H-chromen-2-one (4b). Yield 45\% (3b:4b 83:17); light yellow solid; $\mathrm{mp} 191-203{ }^{\circ} \mathrm{C}$ (from EtOAc-Hexanes); $\mathrm{R}_{f}$ (3b) 0.30, $\mathrm{R}_{f}$ (4b) 0.23 (20\% EtOAc/hexanes); IR (KBr): $v_{\max } 3226,2968,1661,1599,1567,1393,1326,1279,1114,915,842,805 \mathrm{~cm}^{-1}$; ${ }^{1} \mathrm{H}$ NMR $\left(400 \mathrm{MHz}\right.$, DMSO- $\left.d_{6}\right): \delta 10.42(\mathrm{~s}, 1 \mathrm{H}), 7.52(\mathrm{~d}, J 8.8 \mathrm{~Hz}, 1 \mathrm{H}), 6.86(\mathrm{~d}, J 8.8 \mathrm{~Hz}, 1 \mathrm{H}), 6.05(\mathrm{~s}, 1 \mathrm{H}), 6.12-$ $5.83(\mathrm{~m}, 1 \mathrm{H}), 5.07-4.89(\mathrm{~m}, 2 \mathrm{H}), 3.43(\mathrm{~d}, J 1.2 \mathrm{~Hz}, 2 \mathrm{H}), 2.68(\mathrm{t}, J 7.2 \mathrm{~Hz}, 2 \mathrm{H}), 1.61(\mathrm{sext}, J 7.6 \mathrm{~Hz}, 2 \mathrm{H}), 0.95$ (t, J $7.6 \mathrm{~Hz}, 3 \mathrm{H}$ ); ${ }^{13} \mathrm{C}$ NMR $\left(100 \mathrm{MHz}\right.$, DMSO-d $\left.d_{6}\right): \delta 160.88$ (C), 159.10 (C), 157.63 (C), 153.38 (C), 135.90 (CH), 124.13 $(\mathrm{CH}), 116.14(\mathrm{C}), 115.52\left(\mathrm{CH}_{2}\right), 113.42(\mathrm{CH}), 112.55(\mathrm{CH}), 111.77(\mathrm{CH}), 109.53(\mathrm{C}), 33.43\left(\mathrm{CH}_{2}\right), 27.04\left(\mathrm{CH}_{2}\right)$, $21.93\left(\mathrm{CH}_{2}\right), 14.14\left(\mathrm{CH}_{3}\right) ; \mathrm{MS}\left(\mathrm{ESI}^{+}\right) \mathrm{m} / \mathrm{z}(\%) 245.2\left(\mathrm{M}+\mathrm{H}^{+}, 100\right)$.

8-Allyl-7-hydroxy-4-phenyl-2H-chromen-2-one (3c) and 6-allyl-7-hydroxy-4-phenyl-2H-chromen-2-one (4c). Yield 63\% (3c:4c 82:18); light yellow solid; $\mathrm{mp} 188-190{ }^{\circ} \mathrm{C}$ (from EtOAc-Hexanes); $R_{f}$ (3c) $0.33, R_{f}$ (4c) 0.20 (20\% EtOAc/hexanes); IR (KBr): $v_{\max } 3376,3120,2950,1679,1610,1592,1376,1315,1260,1141,1060,995 \mathrm{~cm}^{-1} ;{ }^{1} \mathrm{H}$ NMR (400 MHz, DMSO-d $\left.d_{6}\right): \delta 10.59(\mathrm{~s}, 1 \mathrm{H}), 7.65-7.32(\mathrm{~m}, 5 \mathrm{H}), 7.13(\mathrm{~d}, J 8.8 \mathrm{~Hz}, 1 \mathrm{H}), 6.83(\mathrm{~d}, J 8.8 \mathrm{~Hz}, 1 \mathrm{H}), 6.10$ $(\mathrm{s}, 1 \mathrm{H}), 6.00-5.78(\mathrm{~m}, 1 \mathrm{H}), 5.10-4.80(\mathrm{~m}, 2 \mathrm{H}), 3.46(\mathrm{~d}, J 6.0 \mathrm{~Hz}, 2 \mathrm{H}) ;{ }^{13} \mathrm{C} \mathrm{NMR}\left(100 \mathrm{MHz}, \mathrm{DMSO}-d_{6}\right): \delta 160.60(\mathrm{C})$, 159.49 (C), 156.34 (C), $153.75(\mathrm{C}), 135.90(\mathrm{C}), 135.78(\mathrm{CH}), 129.92(\mathrm{CH}), 128.87(2 \mathrm{CH}), 128.81(2 \mathrm{CH}), 126.08$ $(\mathrm{CH}), 115.69\left(\mathrm{CH}_{2}\right), 113.78(\mathrm{C}), 112.78(\mathrm{CH}), 111.31(\mathrm{C}), 110.53(\mathrm{CH}), 27.09\left(\mathrm{CH}_{2}\right) ; \mathrm{MS}(\mathrm{ESI})^{+} \mathrm{m} / \mathrm{z}(\%) 279.4$ $\left(\mathrm{M}+\mathrm{H}^{+}, 100\right)$.

General procedure for allylation of the mixtures of 3a-c and 4a-c. The synthesis was carried out from the mixture of 3a-c and 4a-c, anhydrous $\mathrm{K}_{2} \mathrm{CO}_{3}$ and allyl bromide in acetone using the above general procedure for the synthesis of compounds $\mathbf{2 a - c}$. The diene products $\mathbf{5 a - c}$ and $\mathbf{6 a}-\mathbf{c}$ were obtained after purification by column chromatography or preparative TLC using EtOAc/hexane as eluent.

8-Allyl-7-(allyloxy)-4-methyl-2H-chromen-2-one (5a). Yield 67\%; light yellow solid; mp 85-86 ${ }^{\circ} \mathrm{C}$ (from EtOACHexanes) [lit ${ }^{25} \mathrm{mp} 92-93{ }^{\circ} \mathrm{C}$ (from acetone)]; $\mathrm{R}_{f} 0.72$ (33\% EtOAc/hexanes); IR (KBr): $v_{\max } 2965,2924,2855$, $1716,1605,1385,1278,1123,1056,844,813 \mathrm{~cm}^{-1} ;{ }^{1} \mathrm{H}$ NMR $\left(400 \mathrm{MHz}, \mathrm{CDCl}_{3}\right): \delta 7.45$ (d, J $\left.8.8 \mathrm{~Hz}, 1 \mathrm{H}\right), 6.86$ (d, J $8.8 \mathrm{~Hz}, 1 \mathrm{H}), 6.15(\mathrm{~s}, 1 \mathrm{H}), 6.14-5.90(\mathrm{~m}, 2 \mathrm{H}), 5.45(\mathrm{dd}, J 17.2,1.6 \mathrm{~Hz}, 1 \mathrm{H}), 5.33(\mathrm{dd}, J 10.6,1.4 \mathrm{~Hz}, 1 \mathrm{H}), 5.10$ (dd, J 17.1, $1.7 \mathrm{~Hz}, 1 \mathrm{H}$ ), 5.00 (dd, J 10.1, 1.6 Hz, $1 \mathrm{H}$ ), $4.67(\mathrm{~d}, J 4.8 \mathrm{~Hz}, 2 \mathrm{H}), 3.66$ (d, J $6.4 \mathrm{~Hz}, 2 \mathrm{H}), 2.41(\mathrm{~s}, 3 \mathrm{H}) ;{ }^{13} \mathrm{C} \mathrm{NMR}$ $\left(100 \mathrm{MHz}, \mathrm{CDCl}_{3}\right): \delta 161.01$ (C), 159.17 (C), 152.63 (C), 152.21 (C), $135.24(\mathrm{CH}), 132.70(\mathrm{CH}), 123.00(\mathrm{CH})$, $117.54\left(\mathrm{CH}_{2}\right), 116.84(\mathrm{C}), 115.29\left(\mathrm{CH}_{2}\right), 114.15(\mathrm{C}), 112.24(\mathrm{CH}), 108.33(\mathrm{CH}), 69.42\left(\mathrm{CH}_{2}\right), 27.06\left(\mathrm{CH}_{2}\right), 18.46$ $\left(\mathrm{CH}_{3}\right) ; \mathrm{MS}\left(\mathrm{ESI}^{+}\right) \mathrm{m} / \mathrm{z}(\%) 257.5\left(\mathrm{M}+\mathrm{H}^{+}, 100\right)$.

6 -Allyl-7 -( allyloxy)-4 -methyl-2 $\mathrm{H}$-chromen-2 -one (6a). Yield 9\%; white solid; mp 103-104 ${ }^{\circ} \mathrm{C}$ (from EtOACHexanes); $R_{f} 0.63$ (33\% EtOAc/hexanes); IR (KBr): $v_{\max } 3071,2923,1730,1613,1385,1367,1274,1163,1065$, 991, 901, 880, $845 \mathrm{~cm}^{-1} ;{ }^{1} \mathrm{H}$ NMR $\left(400 \mathrm{MHz}, \mathrm{CDCl}_{3}\right): \delta 7.34(\mathrm{~s}, 1 \mathrm{H}), 6.80(\mathrm{~s}, 1 \mathrm{H}), 6.14(\mathrm{~s}, 1 \mathrm{H}), 6.12-5.92(\mathrm{~m}, 2 \mathrm{H})$, $5.47(\mathrm{dd}, J 17.2,1.6 \mathrm{~Hz}, 1 \mathrm{H}), 5.35(\mathrm{dd}, J 10.6,1.4 \mathrm{~Hz}, 1 \mathrm{H}), 5.18-5.06(\mathrm{~m}, 2 \mathrm{H}), 4.63(\mathrm{~d}, J 5.2 \mathrm{~Hz}, 2 \mathrm{H}), 3.46$ (d, J 6.6 $\mathrm{Hz}, 2 \mathrm{H}), 2.41$ (s, 3H); ${ }^{13} \mathrm{C} \mathrm{NMR}\left(100 \mathrm{MHz}, \mathrm{CDCl}_{3}\right): \delta 161.34$ (C), 159.24 (C), 153.96 (C), 152.51 (C), 136.09 (CH), $132.25(\mathrm{CH}), 125.94(\mathrm{C}), 124.96(\mathrm{CH}), 117.92\left(\mathrm{CH}_{2}\right), 116.13\left(\mathrm{CH}_{2}\right), 113.14(\mathrm{C}), 111.93(\mathrm{CH}), 99.89(\mathrm{CH}), 69.19$ 
$\left(\mathrm{CH}_{2}\right), 34.00\left(\mathrm{CH}_{2}\right), 18.58\left(\mathrm{CH}_{3}\right) ; \mathrm{MS}\left(\mathrm{ESI}^{+}\right) \mathrm{m} / \mathrm{z}(\%) 257.5\left(\mathrm{M}+\mathrm{H}^{+}, 100\right)$; HRMS (MALDI-TOF): calcd for $\mathrm{C}_{16} \mathrm{H}_{16} \mathrm{NaO}_{3}$ $[\mathrm{M}+\mathrm{Na}]^{+}:$279.0997; found: 279.0995.

8 -Allyl-7 -( allyloxy)-4 -propyl-2 $\mathbf{H}$-chromen-2 -one (5b). Yield 70\%; white solid; mp 70-72 ${ }^{\circ} \mathrm{C}$ (from EtOAcHexanes); $\mathrm{R}_{f} 0.27$ (5\% EtOAc/hexanes); IR (KBr): $v_{\max }$ 3090, 3072, 2964, 2924, 2863, 1716, 1605, 1301, 1279, 1127, 1047, 913, $841 \mathrm{~cm}^{-1} ;{ }^{1} \mathrm{H}-\mathrm{NMR}\left(400 \mathrm{MHz}, \mathrm{CDCl}_{3}\right): \delta 7.48(\mathrm{~d}, J 8.8 \mathrm{~Hz}, 1 \mathrm{H}), 6.86(\mathrm{~d}, J 8.8 \mathrm{~Hz}, 1 \mathrm{H}), 6.16(\mathrm{~s}, 1 \mathrm{H})$, 6.12-5.91 (m, 2H), 5.46 (dd, J 17.2, $1.2 \mathrm{~Hz}, 1 \mathrm{H}), 5.33$ (dd, J 10.4, $1.2 \mathrm{~Hz}, 1 \mathrm{H}) 5.12$ (dd, J 17.0, $1.4 \mathrm{~Hz}, 1 \mathrm{H}) 5.01$ (dd, J 10.0, 0.8 Hz, 1H), $4.67(\mathrm{~d}, J 4.8 \mathrm{~Hz}, 2 \mathrm{H}), 3.67(\mathrm{~d}, J 6.4 \mathrm{~Hz}, 2 \mathrm{H}), 2.72(\mathrm{t}, J 7.6 \mathrm{~Hz}, 2 \mathrm{H}), 1.75($ sext, J $7.6 \mathrm{~Hz}$, 2H), 1.07 (t, J $7.4 \mathrm{~Hz}, 3 \mathrm{H}) ;{ }^{13} \mathrm{C} \mathrm{NMR}\left(100 \mathrm{MHz}, \mathrm{CDCl}_{3}\right): \delta 161.29$ (C), 159.00 (C), 156.04 (C), 152.86 (C), 135.26 $(\mathrm{CH}), 132.72(\mathrm{CH}), 122.82(\mathrm{CH}), 117.54\left(\mathrm{CH}_{2}\right), 116.97(\mathrm{C}), 115.31\left(\mathrm{CH}_{2}\right), 113.48(\mathrm{C}), 111.15(\mathrm{CH}), 108.29(\mathrm{CH})$, $\left.69.40\left(\mathrm{CH}_{2}\right), 33.78\left(\mathrm{CH}_{2}\right), 27.11\left(\mathrm{CH}_{2}\right), 21.55\left(\mathrm{CH}_{2}\right), 13.82\left(\mathrm{CH}_{3}\right) ; \mathrm{MS}(\mathrm{ESI})^{+}\right) \mathrm{m} / z(\%) 285.1\left(\mathrm{M}+\mathrm{H}^{+}, 100\right) ; \mathrm{HRMS}$ (MALDI-TOF): calcd for $\mathrm{C}_{18} \mathrm{H}_{20} \mathrm{NaO}_{3}[\mathrm{M}+\mathrm{Na}]^{+}:$307.1310; found: 307.1313 .

6-Allyl-7-(allyloxy)-4-propyl-2H-chromen-2-one (6b). Yield 13\%; light yellow solid; mp 60-62 ${ }^{\circ} \mathrm{C}$ (from EtOAcHexanes); $\mathrm{R}_{f} 0.20$ (5\% EtOAc/hexanes); IR (KBr): $v_{\max } 3059,2930,1726,1618,1382,1271,1163,1105,986 \mathrm{~cm}^{-}$ 1; ${ }^{1} \mathrm{H}$ NMR $\left(400 \mathrm{MHz}, \mathrm{CDCl}_{3}\right): \delta 7.37(\mathrm{~s}, 1 \mathrm{H}), 6.81(\mathrm{~s}, 1 \mathrm{H}), 6.14(\mathrm{~s}, 1 \mathrm{H}), 6.12-5.90(\mathrm{~m}, 2 \mathrm{H}), 5.47(\mathrm{dd}, J 17.2,1.2 \mathrm{~Hz}$, $2 \mathrm{H}), 5.35(\mathrm{dd}, J 10.8,1.2 \mathrm{~Hz}, 2 \mathrm{H}), 5.13(\mathrm{~s}, 1 \mathrm{H}), 5.12-5.05(\mathrm{~m}, 1 \mathrm{H}), 4.63(\mathrm{~d}, J 5.2 \mathrm{~Hz}, 2 \mathrm{H}), 3.46(\mathrm{~d}, J 6.4 \mathrm{~Hz}, 2 \mathrm{H})$, $2.72(\mathrm{t}, J 7.6 \mathrm{~Hz}, 2 \mathrm{H}), 1.74$ (sext, J $7.5 \mathrm{~Hz}, 2 \mathrm{H}), 1.07$ (t, J $7.4 \mathrm{~Hz}, 3 \mathrm{H}) ;{ }^{13} \mathrm{C} \mathrm{NMR}\left(100 \mathrm{MHz}, \mathrm{CDCl}_{3}\right): \delta 161.60(\mathrm{C})$, 159.09 (C), 156.25 (C), 154.20 (C), $136.12(\mathrm{CH}), 132.27(\mathrm{CH}), 125.85(\mathrm{C}), 124.77(\mathrm{CH}), 117.92\left(\mathrm{CH}_{2}\right), 116.11$ $\left(\mathrm{CH}_{2}\right), 112.50(\mathrm{C}), 110.81(\mathrm{CH}), 100.09(\mathrm{CH}), 69.18\left(\mathrm{CH}_{2}\right), 34.00\left(\mathrm{CH}_{2}\right), 33.70\left(\mathrm{CH}_{2}\right), 21.39\left(\mathrm{CH}_{2}\right), 13.86\left(\mathrm{CH}_{3}\right) ; \mathrm{MS}$ $\left(E S I^{+}\right) \mathrm{m} / \mathrm{z}$ (\%) $285.1\left(\mathrm{M}+\mathrm{H}^{+}, 100\right)$; HRMS (MALDI-TOF): calcd for $\mathrm{C}_{18} \mathrm{H}_{20} \mathrm{NaO}_{3}[\mathrm{M}+\mathrm{Na}]^{+}$: 307.1310; found: 307.1303.

8 -Allyl-7 -( allyloxy)-4 -phenyl-2 H-chromen-2 -one (5c). Yield 64\%; white solid; mp 101-103 ${ }^{\circ} \mathrm{C}$ (from EtOAcHexanes); $\mathrm{R}_{f} 0.30$ (10\% EtOAc/hexanes); IR (KBr): $v_{\max } 3084,3061,2926,1716,1605,1558,1424,1374,1277$, $1118,1069,910,861,773,700 \mathrm{~cm}^{-1} ;{ }^{1} \mathrm{H}-\mathrm{NMR}\left(400 \mathrm{MHz}, \mathrm{CDCl}_{3}\right): \mu 7.62-7.39(\mathrm{~m}, 5 \mathrm{H}), 7.32(\mathrm{~d}, J 8.8 \mathrm{~Hz}, 1 \mathrm{H}), 6.80$ (d, J $8.8 \mathrm{~Hz}, 1 \mathrm{H}), 6.24(\mathrm{~s}, 1 \mathrm{H}), 6.18-5.93(\mathrm{~m}, 2 \mathrm{H}), 5.47(\mathrm{dd}, J 17.3,1.3 \mathrm{~Hz}, 1 \mathrm{H}), 5.43(\mathrm{dd}, J 10.6,1.0 \mathrm{~Hz}, 1 \mathrm{H}) 5.34$ (dd, J 17.1, $1.4 \mathrm{~Hz}, 1 \mathrm{H}) 5.32(\mathrm{dd}, J 10.0,1.1 \mathrm{~Hz}, 1 \mathrm{H}), 4.66(\mathrm{~d}, J 5.0 \mathrm{~Hz}, 2 \mathrm{H}), 3.72(\mathrm{~d}, J 6.4 \mathrm{~Hz}, 2 \mathrm{H}) ;{ }^{13} \mathrm{C} \mathrm{NMR}(100$ $\left.\mathrm{MHz}, \mathrm{CDCl}_{3}\right): \mu 160.94$ (C), 159.30 (C), 155.85 (C), 153.22 (C), 135.98 (C), $135.16(\mathrm{CH}), 132.64(\mathrm{CH}), 129.32(\mathrm{CH})$, $128.67(2 \mathrm{CH}), 128.37(2 \mathrm{CH}), 125.71(\mathrm{CH}), 117.60\left(\mathrm{CH}_{2}\right), 117.04(\mathrm{C}), 115.42\left(\mathrm{CH}_{2}\right), 113.22(\mathrm{C}), 112.15(\mathrm{CH})$, $108.34(\mathrm{CH}), 69.42\left(\mathrm{CH}_{2}\right), 27.14\left(\mathrm{CH}_{2}\right) ; \mathrm{MS}\left(\mathrm{ESI}^{+}\right) \mathrm{m} / \mathrm{z}(\%) 274.7(23), 319.5\left(\mathrm{M}+\mathrm{H}^{+}, 100\right)$; HRMS (MALDI-TOF): calcd for $\mathrm{C}_{21} \mathrm{H}_{18} \mathrm{NaO}_{3}[\mathrm{M}+\mathrm{Na}]^{+}:$341.1154; found: 341.1135 .

6-Allyl-7-(allyloxy)-4-phenyl-2H-chromen-2-one (6c). Yield 15\%; viscous liquid; $\mathrm{R}_{f} 0.23$ (10\% EtOAc/hexanes); IR (ATR): $v_{\max } 3071,2989,2850,1714,1614,1548,1445,1368,1273,1152,992,911,852,769,699 \mathrm{~cm}^{-1} ;{ }^{1} \mathrm{H}$ NMR $\left(400 \mathrm{MHz}, \mathrm{CDCl}_{3}\right): \mu$ 7.60-7.34 (m, 5H), $7.23(\mathrm{~s}, 1 \mathrm{H}), 6.86(\mathrm{~s}, 1 \mathrm{H}), 6.21(\mathrm{~s}, 1 \mathrm{H}), 6.12-5.99(\mathrm{~m}, 1 \mathrm{H}), 5.99-5.81$ $(\mathrm{m}, 1 \mathrm{H}), 5.46(\mathrm{dd}, J$ 17.2, $1.2 \mathrm{~Hz}, 1 \mathrm{H}), 5.34(\mathrm{dd}, J$ 10.8, $1.2 \mathrm{~Hz}, 1 \mathrm{H}), 5.01(\mathrm{~s}, 1 \mathrm{H}), 5.00-4.90(\mathrm{~m}, 1 \mathrm{H}), 4.64(\mathrm{~d}, J 4.8$ $\mathrm{Hz}, 2 \mathrm{H}), 3.35$ (d, J $6.4 \mathrm{~Hz}, 2 \mathrm{H}) ;{ }^{13} \mathrm{C} N M R\left(100 \mathrm{MHz}, \mathrm{CDCl}_{3}\right): \mu 161.11$ (C), 159.48 (C), 155.70 (C), 154.75 (C), $136.01(\mathrm{CH}), 135.82(\mathrm{C}), 132.24(\mathrm{CH}), 129.43(\mathrm{CH}), 128.72(2 \mathrm{CH}), 128.35(2 \mathrm{CH}), 127.36(\mathrm{CH}), 126.09(\mathrm{C}), 117.93$ $\left(\mathrm{CH}_{2}\right), 115.80\left(\mathrm{CH}_{2}\right), 112.11(\mathrm{C}), 111.99(\mathrm{CH}), 100.22(\mathrm{CH}), 69.29\left(\mathrm{CH}_{2}\right), 33.91\left(\mathrm{CH}_{2}\right) ; \mathrm{MS}(\mathrm{ESI})^{+} \mathrm{m} / \mathrm{z}(\%) 274.2$ (100), 305.3 (25), $318.6\left(\mathrm{M}^{+}, 32\right)$; HRMS (MALDI-TOF): calcd for $\mathrm{C}_{21} \mathrm{H}_{18} \mathrm{NaO}_{3}[\mathrm{M}+\mathrm{Na}]^{+}$: 341.1154; found: 341.1144.

General procedure for ring-closing metathesis of $\mathbf{5 a - c}$ and $6 a-c$. The solution of Grubbs' first-generation catalyst (4 mg, $0.9 \mathrm{~mol} \%)$ in dry dichloromethane (DCM) $(10 \mathrm{~mL})$ was added to a solution of 5 or 6 (0.5 mmol) in dry DCM $(40 \mathrm{~mL})$ under $\mathrm{N}_{2}$ atmosphere. The solution was stirred at room temperature for $24 \mathrm{~h}$. After the evaporation of the solvent, the residue was separated by CC using EtOAc/hexane as eluent to give the oxepinocoumarins (7 or $\mathbf{8}) .^{25,26}$ 
4-Methyl-8,11-dihydro-2 H-oxepino[2,3-h]chromen-2-one (7a). Yield 82\%; white solid; mp $118-120^{\circ} \mathrm{C}$ (from EtOAc-Hexanes) [lit ${ }^{26} \mathrm{mp} 109-111{ }^{\circ} \mathrm{C}$ (from DCM)]; $\mathrm{R}_{f} 0.33$ (2 $0 \%$ EtOAc/hexanes); IR (KBr): $v_{\max } 3082,3025$, 2979, 2927, 2837, 1727, 1708, 1598, 1425, 1385, 1270, 1077, $855 \mathrm{~cm}^{-1},{ }^{1} \mathrm{H}-\mathrm{NMR}\left(400 \mathrm{MHz}, \mathrm{CDCl}_{3}\right): \delta 7.42(\mathrm{~d}, J$ $8.6 \mathrm{~Hz}, 1 \mathrm{H}), 7.01(\mathrm{~d}, J 8.6 \mathrm{~Hz}, 1 \mathrm{H}), 6.20(\mathrm{~d}, J 1.2 \mathrm{~Hz}, 1 \mathrm{H}), 6.00-5.82(\mathrm{~m}, 1 \mathrm{H}), 5.62-5.49(\mathrm{~m}, 1 \mathrm{H}), 4.71-4.59(\mathrm{~m}, 2 \mathrm{H})$ 3.88-3.73 (m, 2H), $2.41(\mathrm{~s}, 3 \mathrm{H}) ;{ }^{13} \mathrm{C}$ NMR (100 MHz, CDCl$): \delta 162.03$ (C), 160.69 (C), 152.38 (C), 151.09 (C), $127.30(\mathrm{CH}), 126.33(\mathrm{CH}), 123.32(\mathrm{C}), 123.16(\mathrm{CH}), 117.72(\mathrm{CH}), 116.33(\mathrm{C}), 113.08(\mathrm{CH}), 70.79\left(\mathrm{CH}_{2}\right), 22.49$ $\left(\mathrm{CH}_{2}\right), 18.65\left(\mathrm{CH}_{3}\right) ; \mathrm{MS}\left(\mathrm{ESI}^{+}\right) \mathrm{m} / \mathrm{z}(\%) 229.1\left(\mathrm{M}+\mathrm{H}^{+}, 100\right)$.

4-Propyl-8,11-dihydro-2H-oxepino[2,3-h]chromen-2-one (7b). Yield 69\%; light yellow solid; $\mathrm{mp} 85-87^{\circ} \mathrm{C}$ (from EtOAc-Hexanes); $\mathrm{R}_{f} 0.53$ (20\% EtOAc/hexanes); IR (KBr): $v_{\max } 2959,2924,2853,1708,1622,1272,1154,1132$, 1058, 1022, $842 \mathrm{~cm}^{-1}$; ${ }^{1} \mathrm{H}-\mathrm{NMR}\left(400 \mathrm{MHz}, \mathrm{CDCl}_{3}\right): \delta 7.46(\mathrm{~d}, J 8.8 \mathrm{~Hz}, 1 \mathrm{H}), 7.00(\mathrm{~d}, J 8.8 \mathrm{~Hz}, 1 \mathrm{H}), 6.19(\mathrm{~s}, 1 \mathrm{H})$, 6.01-5.82 (m, 1H), 5.68-5.49 (m, 1H), 4.71-4.59 (m, 2H) 3.88-3.71 (m, 2H), 2.72 (t, J 7.6 Hz, 2H), 1.73 (sext, J 7.6 $\mathrm{Hz}, 2 \mathrm{H}$ ), 1.05 (t, J $7.4 \mathrm{~Hz}, 3 \mathrm{H}) ;{ }^{13} \mathrm{C}$ NMR (100 MHz, CDCl 3 ): $\delta 161.85$ (C), 160.97 (C), 156.20 (C), 151.32 (C), $127.30(\mathrm{CH}), 126.33(\mathrm{CH}), 123.49(\mathrm{C}), 122.98(\mathrm{CH}), 117.67(\mathrm{CH}), 115.68(\mathrm{C}), 112.00(\mathrm{CH}), 70.78\left(\mathrm{CH}_{2}\right), 33.93$ $\left(\mathrm{CH}_{2}\right), 22.53\left(\mathrm{CH}_{2}\right), 21.52\left(\mathrm{CH}_{2}\right), 13.79\left(\mathrm{CH}_{3}\right) ; \mathrm{MS}\left(\mathrm{ESI}{ }^{+}\right) \mathrm{m} / \mathrm{z}(\%) 257.0\left(\mathrm{M}+\mathrm{H}^{+}, 100\right)$; HRMS (MALDI-TOF): calcd for $\mathrm{C}_{16} \mathrm{H}_{16} \mathrm{NaO}_{3}[\mathrm{M}+\mathrm{Na}]^{+}:$279.0997; found: 279.0990.

4-Phenyl-8,1 1 -dihydro-2 $\mathbf{H}$-oxepino[2,3-h]chromen-2-one (7c). Yield 65\%; white solid; mp $118-120{ }^{\circ} \mathrm{C}$ (from EtOAc-Hexanes); $\mathrm{R}_{f} 0.47$ (20\% EtOAc/hexanes); IR ( $\left.\mathrm{KBr}\right): v_{\max } 3070,3028,2924,2854,1723,1597,1370,1260$, 1073, $708 \mathrm{~cm}^{-1} ;{ }^{1} \mathrm{H}-\mathrm{NMR}\left(400 \mathrm{MHz}, \mathrm{CDCl}_{3}\right): \delta 7.61-7.39(\mathrm{~m}, 5 \mathrm{H}), 7.32(\mathrm{~d}, J 8.6 \mathrm{~Hz}, 1 \mathrm{H}), 6.97(\mathrm{~d}, J 8.6 \mathrm{~Hz}, 1 \mathrm{H}), 6.30$ $(\mathrm{s}, 1 \mathrm{H}), 6.10-5.89(\mathrm{~m}, 1 \mathrm{H}), 5.70-5.53(\mathrm{~m}, 1 \mathrm{H}), 4.79-4.60(\mathrm{~m}, 2 \mathrm{H}) 3.98-3.80(\mathrm{~m}, 2 \mathrm{H}) ;{ }^{13} \mathrm{C} \mathrm{NMR}\left(100 \mathrm{MHz}^{\left.\mathrm{C} C \mathrm{Cl}_{3}\right): \delta}\right.$ $162.16(\mathrm{C}), 160.66$ (C), 156.02 (C), 151.70 (C), 135.77 (C), $129.45(\mathrm{CH}), 128.75(2 \mathrm{CH}), 128.36(2 \mathrm{CH}), 127.34(\mathrm{CH})$, $126.41(\mathrm{CH}), 125.86(\mathrm{CH}), 123.38(\mathrm{C}), 117.72(\mathrm{CH}), 115.43(\mathrm{C}), 113.06(\mathrm{CH}), 70.75\left(\mathrm{CH}_{2}\right), 22.56\left(\mathrm{CH}_{2}\right)$; $\left.\mathrm{MS}_{(\mathrm{ESI}}\right)^{+}$ $\mathrm{m} / \mathrm{z}$ (\%) $291.1\left(\mathrm{M}+\mathrm{H}^{+}, 100\right)$; HRMS (MALDI-TOF): calcd for $\mathrm{C}_{19} \mathrm{H}_{14} \mathrm{NaO}_{3}[\mathrm{M}+\mathrm{Na}]^{+}:$313.0841; found: 313.0838.

4 -Methyl-6,9 -dihydro-2 H-oxepino[3,2 -g]chromen-2 -one (8a). Yield 78\%; white solid; mp 168-169 ${ }^{\circ} \mathrm{C}$ (from EtOAc-Hexanes); $\mathrm{R}_{f} 0.27$ (20\% EtOAc/hexanes); IR (KBr): $v_{\max } 3055,3024,2928,2850,1709,1611,1389,1362$, 1151, 1135, $1067 \mathrm{~cm}^{-1} ;{ }^{1} \mathrm{H}-\mathrm{NMR}\left(400 \mathrm{MHz}, \mathrm{CDCl}_{3}\right): \delta 7.32(\mathrm{~s}, 1 \mathrm{H}), 7.05(\mathrm{~s}, 1 \mathrm{H}), 6.22(\mathrm{~s}, 1 \mathrm{H}), 6.00-5.85(\mathrm{~m}, 1 \mathrm{H})$, 5.61-5.47 (m, 1H), 4.73-4.60 (m, 2H) $3.57(\mathrm{~d}, J 8.2 \mathrm{~Hz}, 2 \mathrm{H}), 2.42(\mathrm{~s}, 3 \mathrm{H}) ;{ }^{13} \mathrm{C} \mathrm{NMR}(100 \mathrm{MHz}, \mathrm{CDCl}): \delta 161.73$ (C), 160.82 (C), 152.60 (C), 151.78 (C), 132.27 (C), $127.11(\mathrm{CH}), 126.02$ (CH), 124.03 (CH), 116.04 (C), 113.69 (CH), $110.10(\mathrm{CH}), 71.40\left(\mathrm{CH}_{2}\right), 31.45\left(\mathrm{CH}_{2}\right), 18.49\left(\mathrm{CH}_{3}\right) ; \mathrm{MS}\left(\mathrm{ESI}^{+}\right) \mathrm{m} / z(\%) 229.1\left(\mathrm{M}+\mathrm{H}^{+}, 100\right)$; HRMS (MALDITOF): calcd for $\mathrm{C}_{14} \mathrm{H}_{12} \mathrm{NaO}_{3}[\mathrm{M}+\mathrm{Na}]^{+}:$251.0684; found: 251.0675.

4 -Propyl-6,9 -dihydro-2 H-oxepino[3 ,2 -g]chromen-2 -one (8b). Yield 64\%; white solid; mp $118-121{ }^{\circ} \mathrm{C}$ (from EtOAc-Hexanes); $\mathrm{R}_{f} 0.30$ (30\% EtOAc/hexanes); IR (KBr): $v_{\max } 2960,2926,2853,1708,1621,1154,842 \mathrm{~cm}^{-1} ;{ }^{1} \mathrm{H}-$ $\mathrm{NMR}\left(400 \mathrm{MHz}, \mathrm{CDCl}_{3}\right): \delta 7.34(\mathrm{~s}, 1 \mathrm{H}), 7.06(\mathrm{~s}, 1 \mathrm{H}), 6.22(\mathrm{~s}, 1 \mathrm{H}), 6.01-5.83(\mathrm{~m}, 1 \mathrm{H}), 5.62-5.45(\mathrm{~m}, 1 \mathrm{H}), 4.75-4.60$ (m, $2 \mathrm{H}) 3.57(\mathrm{~d}, J 3.2 \mathrm{~Hz}, 2 \mathrm{H}), 2.73(\mathrm{t}, J 7.6 \mathrm{~Hz}, 2 \mathrm{H}), 1.75$ (sext, J 7.5 Hz, 2H), $1.08(\mathrm{t}, J 7.4 \mathrm{~Hz}, 3 \mathrm{H}) ;{ }^{13} \mathrm{C} \mathrm{NMR}(100$ $\left.\mathrm{MHz}_{2} \mathrm{CDCl}_{3}\right): \delta 161.56(\mathrm{C}), 161.08(\mathrm{C}), 155.55(\mathrm{C}), 153.84(\mathrm{C}), 132.21(\mathrm{C}), 127.11(\mathrm{CH}), 126.02(\mathrm{CH}), 123.75(\mathrm{CH})$, $115.39(\mathrm{C}), 112.58(\mathrm{CH}), 110.29(\mathrm{CH}), 71.41\left(\mathrm{CH}_{2}\right), 33.73\left(\mathrm{CH}_{2}\right), 31.52\left(\mathrm{CH}_{2}\right), 21.33\left(\mathrm{CH}_{2}\right), 13.79(\mathrm{CH})$; $\left.\mathrm{MS}(\mathrm{ESI})^{+}\right)$ $\mathrm{m} / \mathrm{z}$ (\%) $257.2\left(\mathrm{M}+\mathrm{H}^{+}, 100\right)$; HRMS (MALDI-TOF): calcd for $\mathrm{C}_{16} \mathrm{H}_{16} \mathrm{NaO}_{3}[\mathrm{M}+\mathrm{Na}]^{+}:$: 279.0997; found: 279.0990.

4 -Phenyl-6,9-dihydro-2 H-oxepino[3,2 -g]chromen-2 -one (8c). Yield 79\%; light yellow solid; mp 135-139 ${ }^{\circ} \mathrm{C}$ (from EtOAc-Hexanes); $\mathrm{R}_{f} 0.37$ (20\% EtOAc/hexanes); IR ( KBr): $v_{\max } 3061,2927,2855,1725,1615,1378,1359$, 1275, 1146, $701 \mathrm{~cm}^{-1}$; ${ }^{1} \mathrm{H}-\mathrm{NMR}\left(400 \mathrm{MHz}_{\mathrm{CDCl}}\right): \delta$ 7.62-7.33 (m, 5H), $7.17(\mathrm{~s}, 1 \mathrm{H}), 7.10(\mathrm{~s}, 1 \mathrm{H}), 6.28(\mathrm{~s}, 1 \mathrm{H})$, 5.94-5.78 (m, 1H), 5.60-5.40 (m, 1H), 4.78-4.59 (m, 2H), 3.44 (d, J 3.2 Hz, 2H); ${ }^{13} \mathrm{C} \mathrm{NMR}\left(100 \mathrm{MHz}^{\mathrm{CDCl}}\right)_{3}: \delta$ 161.93 (C), 160.76 (C), 155.34 (C), 154.24 (C), 135.63 (C), 132.21 (C), 129.50 (CH), $128.80(2 \mathrm{CH}), 128.31(2 \mathrm{CH})$, $\left.126.99(\mathrm{CH}), 126.42(\mathrm{CH}), 126.17(\mathrm{CH}), 115.04(\mathrm{C}), 113.73(\mathrm{CH}), 110.30(\mathrm{CH}), 71.36\left(\mathrm{CH}_{2}\right), 31.33\left(\mathrm{CH}_{2}\right) ; \mathrm{MS}_{(\mathrm{ESI}}{ }^{+}\right)$ $\mathrm{m} / \mathrm{z}$ (\%) 274.2 (28), $291.2\left(\mathrm{M}+\mathrm{H}^{+}, 100\right)$; HRMS (MALDI-TOF): calcd for $\mathrm{C}_{19} \mathrm{H}_{14} \mathrm{NaO}_{3}[\mathrm{M}+\mathrm{Na}]^{+}$: 313.0841; found: 313.0842 . 
Cell line maintenance. The Three cancer cell lines used in this study were obtained from ATCC (MD, USA) and are as follows: colorectal adenocarcinoma (Caco-2), hepatocellular carcinoma (HepG2) and breast carcinoma (SKBR-3) cell lines. The Caco-2 and HepG2 cells were cultured in EMEM medium whereas SKBR-3 was cultured in DMEM medium. All media (Gibco, Langley, VA, USA) were supplemented at $10 \%$ with fetal bovine serum (Gibco) and streptomycin plus penicillin (100 $\mathrm{gg} / \mathrm{mL}$ and $100 \mathrm{U} / \mathrm{mL}$, respectively; Sigma Co., Madrid, Spain). All cells were maintained at $37^{\circ} \mathrm{C}, 95 \%$ relative humidity with $5 \% \mathrm{CO}_{2}$ atmosphere.

Evaluation of cell viability. All the candidates oxepin-annulated coumarins 5-8 were evaluated in vitro for their anti-proliferative activity against three different cancer cell lines, colorectal adenocarcinoma (Caco-2), hepatocellular carcinoma (HepG2) and breast carcinoma (SKBR-3) cell lines using the 3-(4,5-dimethylthiazol-2yl)-2,5-diphenyl-2H-tetrazolium bromide (MTT) assay as previously reported technique. ${ }^{44}$ In brief, cells were seeded into 96-well tissue culture plates in appropriated basal medium for each cell line containing $10 \%$ FBS to a final volume of $100 \mu \mathrm{L}$. The cells were subjected to different treatments after $24 \mathrm{~h}$ of seeding. The cells were then incubated for $48 \mathrm{~h}$ with test compounds, tamoxifen as a positive control, or vehicle (DMSO). MTT solutions were then added and cells were incubated for $3 \mathrm{~h}$. After that, the supernatants were removed and the precipitated formazan was dissolved by adding $200 \mu \mathrm{L}$ of DMSO. Absorbance at $570 \mathrm{~nm}$ was determined using a microplate reader (Varioskan ${ }^{\mathrm{TM}}$ Flash Multimode Reader; Thermo Scientific ${ }^{\mathrm{TM}}$ ). Results were calculated by subtracting blank readings.

Data analysis. The $\mathrm{IC}_{50}$ values were obtained from the curve fitted to the means of the absorbance quotients with respect to the control.

\section{Acknowledgements}

This research was supported by Thammasat University under TU research Scholar, Contract No. 2/14/2558. We thank Ms. Duangkamon Saekow for her excellent technical support. We sincerely thank Assoc. Prof. Dr. Kobtham Sathirakul, Mahidol University for providing Caco-2 cell line. We also acknowledge Chulabhorn Research Institute for the HRMS analysis.

\section{Supporting Information}

Supporting Information associated with this article are available: ${ }^{1} \mathrm{H}$ and ${ }^{13} \mathrm{C}$ spectra of compounds $2-8$.

\section{References}

1. Symeonidis, T.; Fylaktakidou, K.C.; Hadjipavlou-Litina, D.J.; Litinas, K.E. Eur. J. Med. Chem. 2009, 44, 5012. https://doi.org/10.1016/i.ejmech.2009.09.004

2. Lee, J.; Lee, Y.J.; Kim, J.; Bang, O.S. Molecules 2015, 20, 20967. https://doi.org/10.3390/molecules201219738

3. Olomola, T.O.; Mosebi, S.; Klein, R.; Traut-Johnstone, T.; Coates, J.; Hewer, R.; Kaye, P.T. Bioorg. Chem. 2014, 57, 1.

https://doi.org/10.3390/molecules201219738 
4. Chauthe, S.K.; Mahajan, S.; Rachamalla, M.; Tikoo, K.; Singh, I.P. Med. Chem. Res. 2015, 24, 2476. https://doi.org/10.1007/s00044-014-1312-6

5. Luo, K.W.; Sun, J.G.; Chan, J.Y.; Yang, L.; Wu, S.H.; Fung, K.P.; Liu, F.Y. Chemotherapy 2011, $57,449$. https://doi.org/10.1159/000331641

6. Piao, X.L.; Park, I.H.; Baek, S.H.; Kim, H.Y.; Park, M.K.; Park, J.H. J. Ethnopharmacol. 2004, 93, 243. https://doi.org/10.1016/j.jep.2004.03.054

7. Song, P.P.; Zhao, J.; Liu, Z.L.; Duan, Y.B.; Hou, Y.P.; Zhao, C.Q.; Wu, M.; Wei, M.; Wang, N.H.; Lv, Y.; Han, Z.J. Pest Manag. Sci. 2017, 73, 94.

https://doi.org/10.1002/ps.4422

8. Kaneria, A.R.; Giri, R.R.; Bhila, V.G.; Prajapati, H.J.; Brahmbhatt, D.I. Arab. J. Chem. 2017, 10, S1100. https://doi.org/10.1016/j.arabjc.2013.01.017

9. Zhang, G.; Zhang, Y.; Yan, J.; Chen, R.; Wang, S.; Ma, Y.; Wang, R. J. Org. Chem. 2012, 77, 878. https://doi.org/10.1021/jo202020m

10. Lipeeva, A.V.; Khvostov, M.V.; Baev, D.S.; Shakirov, M.M.; Tolstikova, T.G.; Shults, E.E. Med. Chem. 2016, $12,674$.

https://doi.org/10.2174/1573406412666160129105115

11. Tosun, F.; Kızılay, Ç.A.; Erol, K.; Kılıç, F.S.; Kürkçüoğlu, M.; Başer, K.H.C. Food Chem. 2008, $107,990$. https://doi.org/10.1016/j.foodchem.2007.08.085

12. Wang, T.; Wang, C.; Zhou, N.; Pan, X.; He, H. Med. Chem. Res. 2015, 24, 2417. https://doi.org/10.1007/s00044-014-1303-7

13. Macías, F.A.; Torres, A.; Galindo, J.L.G.; Varela, R.M.; Álvarez, J.A.; Molinillo, J.M.G. Phytochemistry 2002, $61,687$.

https://doi.org/10.1016/S0031-9422(02)00370-9

14. Bruder, M.; Haseler, P.L.; Muscarella, M.; Lewis, W.; Moody, C.J. J. Org. Chem. 2010, 75, 353. https://doi.org/10.1021/jo902117e

15. Vyvyan, J.R.; Oaksmith, J.M.; Parks, B.W.; Peterson, E.M. Tetrahedron Lett. 2005, 46, 2457. https://doi.org/10.1016/j.tetlet.2005.02.053

16. Zhang, C.L.; Liu, Y.F.; Wang, Y.; Liang, D.; Jiang, Z.B.; Li, L.; Hao, Z.Y.; Luo, H.; Shi, G.R.; Chen, R.Y.; Cao, Z.Y.; Yu, D.Q. Org. Lett. 2015, 17, 5686.

https://doi.org/10.1021/acs.orglett.5b02982

17. Li, H.; Jean, A.; Webster, D.; Robichaud, G.A.; Calhoun, L.A.; Johnson, J.A.; Gray, C.A. J. Nat. Prod. 2015, 78, 2837.

https://doi.org/10.1021/acs.jnatprod.5b00627

18. Trabanco, A.A.; Alonso, J.M.; Andrés, J.I.; Cid, J.M.; Fernández, J.; Iturrino, L.; Megens, A. Chem. Pharm. Bull. 2004, 52, 262.

https://doi.org/10.1248/cpb.52.262

19. Agnew, M.N.; Rizwaniuk, A.; Ong, H.H.; Wichmann, J.K. J. Heterocycl. Chem. 1986, 23, 265. https://doi.org/10.1002/ihet.5570230155

20. Trabanco, A.A.; Alonso, J.M.; Cid, J.M.; Font, L.M.; Megens, A. Farmaco 2005, 60, 241. https://doi.org/10.1016/i.farmac.2004.12.008

21. Jinno, S.; Okita, T. Heterocycles 1999, 51, 303.

https://doi.org/10.3987/COM-98-8390 
22. Kittakoop, P.; Nopichai, S.; Thongon, N.; Charoenchai, P.; Thebtaranonth, Y. Helv. Chim. Acta 2004, 87, 175.

https://doi.org/10.1002/hlca.200490006

23. Pettit, G.R.; Numata, A.; Iwamoto, C.; Usami, Y.; Yamada, T.; Ohishi, H.; Cragg, G.M. J. Nat. Prod. 2006, 69, 323.

https://doi.org/10.1021/np058075+

24. Wang, L.; Xie, S.; Ma, L.; Chen, Y.; Lu W. Bioorg. Med. Chem. 2015, 23, 1950.

https://doi.org/10.1016/i.bmc.2015.03.031

25. Chattopadhyay, S.K.; Maity, S.; Panja, S. Tetrahedron Lett. 2002, 43, 7781.

https://doi.org/10.1016/S0040-4039(02)01806-3

26. Litinas, K.E.; Mangos, A.; Nikkou, T.E.; Hadjipavlou-Litina, D.J. J. Enzyme Inhib. Med. Chem. 2011, $26,805$. https://doi.org/10.3109/14756366.2011.555944

27. Yet, L. Chem. Rev. 2000, 100, 2963.

https://doi.org/10.1021/cr990407q

28. Elliott, M.C. J. Chem. Soc., Perkin Trans. 1, 2000, 1291.

https://doi.org/10.1039/a903885j

29. Nandi, S.; Singha, R.; Ray, J.K. Tetrahedron 2015, 71, 669.

https://doi.org/10.1016/j.tet.2014.12.016

30. Das, S.N.; Chowdhury, A.; Tripathi, N.; Jana, P.K.; Mandal, S.B. J. Org. Chem. 2015, 80, 1136. https://doi.org/10.1021/j0502672x

31. Yadav, D.B.; Taleli, L.; van der Westhuyzen, A.E.; Fernandes, M.A.; Dragoun, M.; Prokop, A.; Schmalz, H.G.; de Koning, C.B.; van Otterlo, W.A.L. Eur. J. Org. Chem. 2015, 5167.

https://doi.org/10.1002/ejoc.201500573

32. Wang, Y.; Chen, Y.; He, Q.; Xie, Y.; Yang, C. Helv. Chim. Acta 2013, 96, 296.

https://doi.org/10.1002/hlca.201200116

33. van Otterlo, W.A.L.; Ngidi, E.L.; Coyanis, E.M.; de Koning, C.B. Tetrahedron Lett. 2003, 44, 311. https://doi.org/10.1016/S0040-4039(02)02522-4

34. Doveston, R.G.; Steendam, R.; Jones, S.; Taylor, R.J.K. Org. Lett., 2012, 14, 1122. https://doi.org/10.1021/ol300039x

35. Nicolaou, K.C.; Bulger, P.G.; Sarlah, D. Angew. Chem. Int. Ed. 2005, 44, 4490. https://doi.org/10.1002/anie.200500369

36. Stenne, B.; Timperio, J.; Savoie, J.; Dudding, T.; Collins, S.K. Org. Lett., 2010, 12, 2032. https://doi.org/10.1021/ol100511d

37. Calder, E.D.D.; Sharif, S.A.I.; McGonagle, F.I.; Sutherland, A. J. Org. Chem. 2015, 80, 4683. https://doi.org/10.1021/acs.joc.5b00583

38. Aderibigbe, B.A.; Green, I.R.; Mabank, T.; van Rensburg, M.J.; Morgans, G.L.; Fernandes, M.A.; Michael, J.P.; van Otterlo, W.A.L. Tetrahedron 2017, 73, 4671.

https://doi.org/10.1016/i.tet.2017.06.039

39. Prateeptongkum, S.; Duangdee, N.; Thongyoo, P. Arkivoc 2015, (v), 248.

http://dx.doi.org/10.3998/ark.5550190.p008.947

40. Geran, R.I.; Greenberg, N.H.; MacDonald, M.M.; Schumaker, A.M.; Abbott, B.J. Cancer Chemother. Rep. 3 1972, 3, 59.

41. Kaufman, K.D. US 3201 421, 1965.

42. Ahluwalia, V.K.; Tripathi, R.P. J. Indian Chem. Soc. 1984, 61, 1023. 
43. Ahuja, M.; Bandopadhyay, M.; Seshadri, T.R. Indian J. Chem. 1974, 12, 292.

44. Scudiero, D.A.; Shoemaker, R.H.; Paull, K.D.; Monks, A.; Tierney, S.; Nofziger, T.H.; Currens, M.J.; Seniff, D.; Boyd, M.R. Cancer Res. 1988, 48, 4827. 